\title{
ASSESSMENT AND PREDICTION OF INDUSTRIAL WORKERS' FATIGUE IN AN OVERHEAD ASSEMBLY JOB
}

\author{
S.A. Binoosh ${ }^{1,2 *}$, G.M. Mohan ${ }^{2} \&$ D. Bijulal ${ }^{1}$
}

\section{ARTICLE INFO}

\section{Article details}

Submitted by authors 5 Dec 2016

Accepted for publication 24 Mar 2017

Available online $\quad 26$ May 2017

\section{Contact details}

Corresponding author

binoosh@cet.ac.in

Author affiliations

1 Department of Mechanical

Engineering, College of

Engineering, Thiruvananthapuram, India

2 Department of Production

Engineering, PSG College of

Technology, Coimbatore, India

\section{DOI}

http://dx.doi.org/10.7166/28-1-1697

\section{ABSTRACT}

This paper intends to predict time-related fatigue experienced among workers involved in the overhead assembly of submersible pumps. Borg's CR-10 scale, the Samn-Perelli fatigue scale (SPFS), and dimensions of the Swedish occupational fatigue inventory (SOFI) were used to assess and predict fatigue. The results of a temporal analysis indicate that fatigue levels in this type of job increase throughout the work at a diminishing rate. Exploratory analysis revealed that Borg's CR-10 scale is more reliable than SPFS in predicting fatigue. It was also observed that the physical discomfort dimension of SOFI is the predominant one for predicting fatigue in the selected task. Older and more experienced groups of workers showed significantly increased fatigue, while body mass index (BMI)based groups did not show such differences.

\section{OPSOMMING}

Hierdie artikel poog om die tyd-verwante uitputting wat deur werkers wat dompelpompe oorhoofs monteer te voorspel. Borg se CR-10 skaal, die Samn-Perelli uitputtingskaal en sekere dimensies van die Sweedse arbeidsuitputtingsinventaris is gebruik om uitputting te beoordeel en te voorspel. Die resultate van ' $n$ temporale analise dui daarop dat uitputtingsvlakke in hierdie tipe werk toeneem teen ' $n$ verminderende tempo. Ondersoekende analise toon dat Borg se CR-10 skaal meer betroubaar as die SamnPerelli skaal is om uitputting te voorspel. Daar is ook waargeneem dat die fisiese ongemak dimensie van die Sweedse arbeidsuitputtingsinventaris die oorheersende dimensie is om uitputting te voorspel vir dié spesifieke taak. Ouer en meer ervare groepe werkers het noemenswaardig verminderde uitputting getoon. Daarteenoor het groepe wat volgens die liggaamsmassaindeks ingedeel is nie sulke verskille aan die lig gebring nie.

\section{INTRODUCTION}

Manufacturing companies have faced intensified competition during the past two decades [1-2]. The stress that manufacturing companies experience due to this intensified competition has in turn been transferred to industrial workers. In order to meet elevated targets, industrial workers are forced to work for longer periods [3]. During working hours, industrial workers are exposed to a number of physical tasks that create fatigue, pain, and discomfort, leading to musculoskeletal disorders (MSDs) [4-6]. In order to cope with the intense competition, complex products requiring the assembly of several components are being produced by manufacturing companies [7]. To meet this challenge, many workers are forced to work on diversified assembly jobs in such companies, leading to MSDs [8].

In certain assembly jobs, industrial workers are subjected to overhead work that requires their hands to operate above shoulder height [9]. Studies indicate that, in the case of overhead work, an early onset of fatigue occurs in workers' shoulder muscles [10-12]. Also, the prevalence of shoulder MSDs and reduced productivity was observed in occupations with overhead work postures [9].The 
flexion/abduction of shoulders above 60 degrees also increases the risk of MSDs for the workers [10]. Work with extreme postures has been reported as one of the main risk factors leading to MSDs, and resulting in postural stresses and fatigue in a variety of industries [13].

Fatigue causes tiredness and exhaustion among the workers, and decreases the normal capabilities of the affected persons [14]. Fatigue generates physiological changes in the workers' bodies that can be measured subjectively by using self-reports with uni-dimensional and multi-dimensional scales [15]. Researchers predominantly use Borg's category ratio scale (CR-10 scale), the SamnPerelli fatigue scale (SPFS) and the Swedish occupational fatigue inventory (SOFI) to measure fatigue. Borg's CR-10 scale is a uni-dimensional scale that can be used to measure the intensity of perceived exertion [16]. It could also be appropriately used to measure perceived fatigue [15, 17]. SPFS is also a uni-dimensional scale that was specifically developed to estimate aircrew fatigue [18]. It is a seven-point scale that represents different stages of fatigue from 'fully alert' to 'stage of exhaustion'. SPFS has also been used to study fatigue during shift work with smelting plant workers [19] and rail industrial workers [20].

SOFI is a self-report instrument with a multi-dimensional scale to measure fatigue [15]. SOFI was developed, based on 25 factors representing fatigue, and formulated with five dimensions of fatigue with factor analysis. The dimensions of SOFI include physical exertion, physical discomfort, lack of energy, lack of motivation, and sleepiness. These dimensions were again modified by refining the number of factors into 20 , and creating a measurement scale with seven points for each factor [2122]. Åhsberg, Gamberale, and Kjellberg [15] revealed that the dimensions encompassed in SOFI such as lack of energy, physical discomfort, and physical exertion - are prominent in physical tasks. In an experimental evaluation of physical fatigue, it was found that static work is mostly related to the 'physical discomfort' dimension of SOFI, while dynamic work is mostly related to 'physical exertion'[21].

The measurement scales discussed above could be used to assess fatigue at any time during working hours [15, 17, 19-20, 22-23]. Most often workers work for long hours to meet production demands. Such long working hours are common all over the world, including in the so-called 'developed' countries; and they give rise to health and social problems for the employees [24-28]. The prediction of fatigue in lengthy periods of work can be determined, based on a temporal assessment using these measurement scales.

Although several studies describing overhead work and MSDs have been reported in the literature [9-13], no studies have reported on the prediction of fatigue in long hours of work. In the present study, Borg's CR-10 scale and SPFS were used to assess and predict fatigue in industrial workers engaged in overhead assembly tasks. The lack of energy (LE) and physical discomfort (PD) dimensions of SOFI were also used in this study to investigate fatigue arising from the stationary nature of assembly jobs. The objective of this study is to predict fatigue in assembly tasks involving overhead work. This study specifically considers industrial workers involved in the assembly of submersible pumps that require overhead work.

\section{MATERIAL AND METHODS}

In order to meet the objectives of the study, a field investigation was conducted in pump manufacturing companies situated in the city of Coimbatore, India. The selection of the subjects, and the assessment of fatigue, are described in the sections that follow.

\subsection{Subjects}

For this study, 30 male subjects who were involved in the assembly of submersible pumps were selected from 16 different pump manufacturing companies, on the basis that they had a minimum of two years' experience in submersible pump assembly job and had no history of MSDs. Their demographic details are shown in Table 1. They had a mean experience of 10.33 years and a mean age of 33.93 years. The height and weight of the subjects had mean values of $166.5 \mathrm{~cm}$ and 60.07 $\mathrm{kg}$ respectively. All were right-handed. 
Table 1: Demographic details of subjects

\begin{tabular}{|llcccc|}
\hline Basic statistics & Age (years) & Experience (years) & Height (cm) & Weight (kg) & BMI (kg/m ${ }^{2}$ ) \\
\hline Mean & 33.93 & 10.33 & 166.50 & 60.07 & 21.62 \\
Standard deviation (SD) & 10.65 & 8.08 & 5.62 & 9.14 & 2.75 \\
Range & $20-53$ & $02-25$ & $158-183$ & $45-79$ & $5.67-26.67$ \\
\hline
\end{tabular}

\subsection{Work task}

The submersible pump is a multi-stage pump. The number of stages increases with delivery requirements. A typical submersible pump assembly is shown in Figure 1.

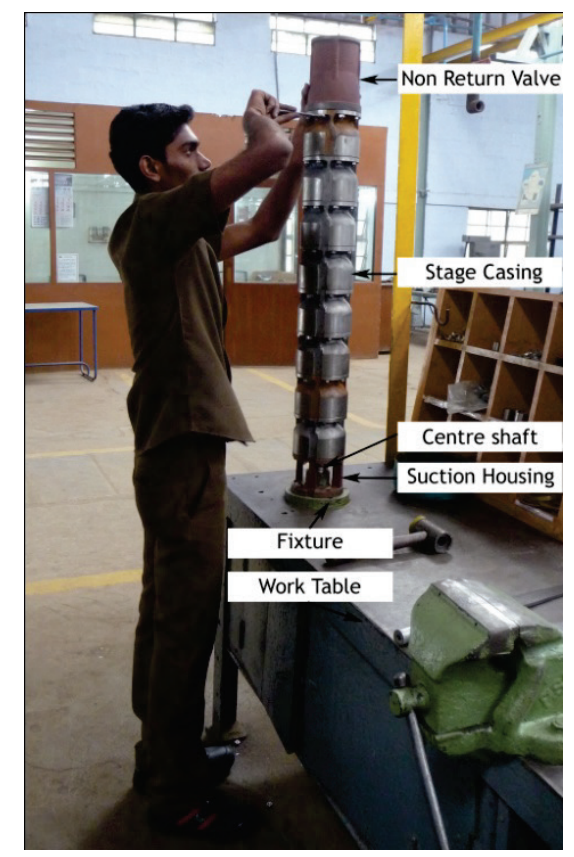

Figure 1: Assembly of an eight-stage submersible pump

The vertical height of the pump ranges from 0.6 meters to 2 meters. The assembly progresses vertically on a fixture mounted on a work table. The centre shaft in the pump occupies about 80 percent of the pump's total height. Components such as the suction housing, sleeve, impeller, and stage casing should be added from the top of the shaft to carry out the assembly. The sleeve and impeller are accommodated inside the stage casing during the assembly. The top component, the non-return valve, is the final component in the assembly process. The worker has to maintain a stationary posture throughout the time it takes to assemble these components. The nature of this task means that the worker has to work overhead and in positions involving extreme reach. For these reasons, this stationary assembly job involving overhead work has been chosen for research in this paper.

\subsection{Data collection procedure}

The relevant data were collected through structured interviews at predefined times. To assess the levels of fatigue and its temporal effects, the working day of eight hours was divided into four periods. Accordingly, the assessments were done during the day shift (a) after two hours of work (that is, before the tea break in the morning session), (b) after four hours of work (that is, before the lunch break), (c) after six hours of work (that is, before the afternoon tea break), and (d) after eight hours of work (that is, at the end of the shift). It was assumed that workers were free from fatigue before starting work. Rest pauses of 15 minutes each for the two tea breaks and 30 minutes for the lunch break were also included in the working day of eight hours. The assessment of fatigue in all of the subjects was conducted using Borg's CR-10 scale [29], SPFS [18], SOFI (LE), and SOFI (PD) [15]. 
Borg's CR-10 scale was used to indicate the perceived exertion, with a scale ranging from no exertion (0) to maximum exertion (10) to rate the fatigue. A scale ranging from ' 1 ' to ' 7 ' was used to rate fatigue in SPFS, with ' 1 ' indicating a fully alert state and ' 7 ' indicating a completely exhausted state. The LE and PD dimensions of SOFI used a scale of ' 0 ' to ' 6 ' to represent the range from 'not at all' to 'a very high degree' for the impression of their respective sub-factors. The sub-factors of the LE dimension included 'worn out', 'spent', 'drained', and 'over-worked', while those of the PD dimension included 'tense muscles', 'numbness', 'stiff joints', and 'aching'. The average of the values obtained for these factors was calculated to obtaining the fatigue value of each dimension. The correlations of the fatigue values at the selected temporal points based on Borg's CR-10 scale, SPFS, and the task-relevant dimensions of SOFI - that is, LE and PD - were determined from the observations. To compare the temporal effects of fatigue, the scales of all the fatigue measures were normalised to a 0-10 scale. Fatigue prediction for the uni-dimensional scales and the relevant dimensions of SOFI were established by linear and quadratic regression models. Fatigue models for demographic groups were also developed.

\subsection{Statistical analysis}

Non-parametric tests were conducted to carry out the analysis, given the small sample size. Spearman's rank correlation was used to analyse the degree of association between the temporal values of fatigue. The Wilcoxon signed-rank test was used to study the significance of the mean increase in the temporal values of fatigue. The correlation of the temporal values of fatigue with the demographic characteristics was also determined. The Mann-Whitney test was used to determine the significance of the difference in fatigue in the age- and experience-based groups. The KruskalWallis test was used to determine the significance of the difference in fatigue among the BMI-based groups. The analysis was done with the help of Minitab ${ }^{\circledR} 15$ software.

\section{RESULTS}

The results are classified and presented in the sections that follow, under headings such as 'the temporal characteristics of fatigue' and 'prediction of fatigue'.

\subsection{The temporal characteristics of fatigue}

The statistics of the results on fatigue obtained by using Borg's CR-10 scale, SPFS, SOFI (LE), and SOFI (PD) are given in Table 2. It reveals that the mean values in all of the fatigue measures were found to increase from the start of work through to the end of the shift - as expected. It is also evident that initial fatigue was accumulated during the first two hours of work. Borg's CR-10 scale indicated a minimum value of 0.3 (less than 'extremely weak exertion') and a maximum value of 8 (more than 'very strong exertion'). SPFS showed a range of values from 2 ('very lively, responsive, but not at peak') to 7 ('completely exhausted, unable to function effectively'). A minimum value of 0.75 (just more than 'not at all') and a maximum value of 6 ('very high degree') was shown in the SOFI (LE) scale. However, the SOFI (PD) dimension of fatigue indicated a minimum value of 0 and a high value of 4 - less than the maximum of the scale.

Table 2: Statistics of fatigue developed in subjects

\begin{tabular}{|clcccc|}
\hline \multirow{2}{*}{ Time spend on work (hours) } & & \multicolumn{5}{c|}{ Fatigue measures } \\
\cline { 3 - 6 } & & Borg's CR-10 scale & SPFS & SOFI (LE) & SOFI (PD) \\
\hline \multirow{2}{*}{2} & Mean & 1.087 & 2.900 & 1.292 & 0.600 \\
& SD & 0.549 & 0.403 & 0.322 & 0.305 \\
& Range & $0.3-3$ & $2-4$ & $0.75-1.75$ & $0.00-1.25$ \\
\hline \multirow{2}{*}{4} & Mean & 2.917 & 4.167 & 2.883 & 1.625 \\
& SD & 0.911 & 0.531 & 0.594 & 0.544 \\
& Range & $1-5$ & $3-5$ & $1.75-4.00$ & $0.50-2.75$ \\
\hline \multirow{2}{*}{6} & Mean & 4.767 & 4.767 & 3.833 & 2.387 \\
& SD & 1.040 & 0.568 & 0.699 & 0.614 \\
& Range & $2-7$ & $3-6$ & $2.25-5.00$ & $1.25-3.50$ \\
\hline \multirow{2}{*}{8} & Mean & 6.300 & 5.767 & 4.750 & 3.067 \\
& SD & 1.343 & 0.568 & 0.864 & 0.716 \\
& Range & $3-8$ & $4-7$ & $2.75-6.00$ & $1.75-4.00$ \\
\hline
\end{tabular}


Spearman's rank correlation coefficient was determined to assess the degree of association between the temporal values of fatigue. These results are presented in Table 3. As shown, a significant ( $p<$ 0.05) correlation exists between all temporal values for Borg's CR-10 scale and SOFI (PD). The correlation is insignificant $(p>0.05)$ between the time-related fatigue values corresponding to two hours and six hours of work, and two hours and eight hours of work. However, according to the results obtained by using SOFI (LE), the correlation is insignificant $(p>0.05)$ only between the value corresponding to two hours and eight hours of work.

Table 3: Temporal correlations in fatigue measures

\begin{tabular}{|lcccc|}
\hline Fatigue measures & $\begin{array}{c}\text { Temporal points } \\
\text { (hours of work) }\end{array}$ & 2 & 4 & 6 \\
\hline Borg's CR-10 & 4 & $0.594^{*}$ & & \\
scale & 6 & $0.508^{*}$ & $0.907^{*}$ & \\
& 8 & $0.463^{*}$ & $0.810^{*}$ & $0.947^{*}$ \\
\hline \multirow{3}{*}{ SPFS } & 4 & $0.537^{*}$ & & \\
& 6 & 0.286 & $0.536^{*}$ & $0.854^{*}$ \\
\hline \multirow{2}{*}{ SOFI (LE) } & 8 & 0.105 & $0.421^{*}$ & \\
& 4 & $0.570^{*}$ & & \\
\hline \multirow{2}{*}{ SOFI (PD) } & 6 & $0.473^{*}$ & $0.941^{*}$ & $0.939^{*}$ \\
& 8 & 0.359 & $0.826^{*}$ & \\
& 4 & $0.857^{*}$ & & \\
& 6 & $0.825^{*}$ & $0.955^{*}$ & $0.979^{*}$ \\
\hline
\end{tabular}

The figures for temporal increase in fatigue obtained by using Borg's CR-10 scale, SPFS, SOFI (LE), and SOFI (PD) are presented in Table 4. It is evident from the table that the increase in the mean value of fatigue from two to four hours of work is higher than that for other periods in all fatigue measures, with the exception of Borg's CR-10 scale. However, the results obtained by using Borg's CR-10 scale indicate a diminishing rate of fatigue in successive periods, based on the percentage of increase. The changes in the temporal values of SOFI (LE) and SOFI (PD) also support the variations observed in Borg's CR-10 scale. The Wilcoxon signed-rank test was used to determine the significance of the increased values in successive periods of the working day. The results of this test indicated a significant increase $(p=0)$ in the temporal values for fatigue in all cases.

Table 4: Temporal increase in fatigue

\begin{tabular}{|llcccc|}
\hline \multirow{2}{*}{ Temporal increase } & \multicolumn{4}{c|}{ Fatigue measures } \\
\cline { 2 - 5 } & & Borg's CR-10 scale & SPFS & SOFI (LE) & SOFI (PD) \\
\hline \multirow{2}{*}{$\begin{array}{l}\text { 2 to 4 hours of } \\
\text { work }\end{array}$} & Mean & 1.83 & 1.27 & 1.59 & 1.03 \\
\cline { 2 - 5 } & Percentage & 168.35 & 43.69 & 123.14 & 170.83 \\
\hline $\begin{array}{l}4 \text { to 6 hours of } \\
\text { work }\end{array}$ & Mean & 1.85 & 0.60 & 0.95 & 0.76 \\
\cline { 2 - 6 } & Percentage & 63.42 & 14.40 & 32.95 & 46.89 \\
\hline $\begin{array}{l}\text { 6 to 8 hours of } \\
\text { work }\end{array}$ & Mean & 1.53 & 1.00 & 0.917 & 0.68 \\
\cline { 2 - 6 } & Percentage & 32.16 & 20.98 & 23.92 & 28.49 \\
\hline
\end{tabular}

The mean increase in the fatigue measure with normalised values during the working day is shown in Figure 2, from which it is evident that the normalised observed values of SPFS are always at higher levels than for other models. Also, the normalised observed values of SOFI (PD) are always at lower levels than other for models. The variation of fatigue in Borg's CR-10 scale seems to be smoother than it is with the other measures. 


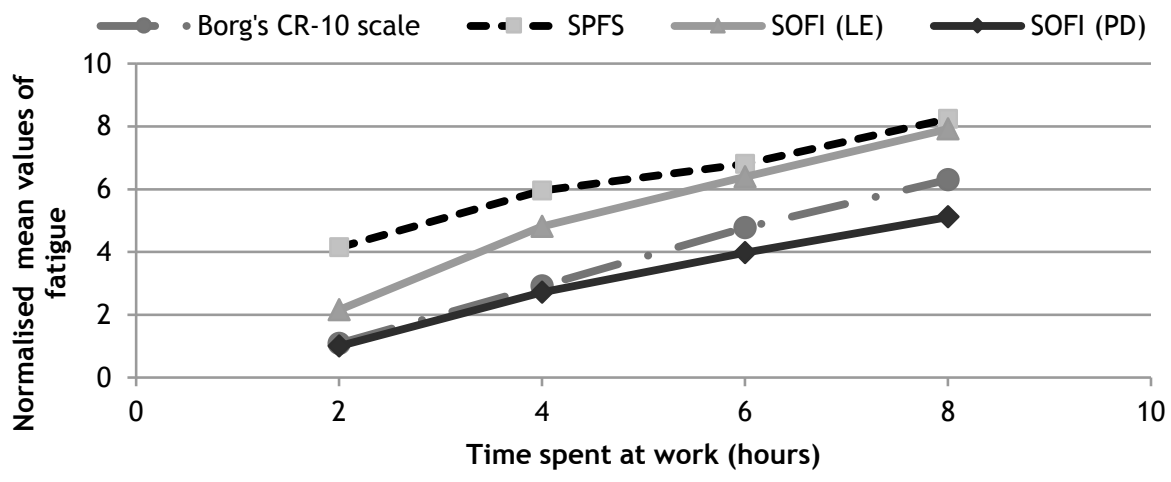

Figure 2: Temporal pattern of fatigue

\subsection{Prediction of fatigue}

In order to choose the method that would be most reliable in predicting fatigue, the standard error (SE) and coefficient of determination $\left(R^{2}\right)$ were determined for linear and quadratic models of regression, based on the mean values of Borg's CR-10 scale and SPFS. The SE and $R^{2}$ of SOFI (LE) and SOFI (PD) were also determined to compare the reliability of these dimensions of fatigue. Equations (1) to (8) below indicate the linear and quadratic regression models obtained for these different scales and dimensions.

$$
\begin{aligned}
& F(B)_{\iota}=-0.605+0.874 t \\
& F(B)_{\mathrm{q}}=-0.976+1.060 t-0.019 t^{2} \\
& F(S)_{l}=2.100+0.460 t \\
& F(S)_{\mathrm{q}}=1.767+0.627 t-0.017 t^{2} \\
& F(L E)_{\iota}=0.358+0.566 t \\
& F(L E)_{q}=-0.485+0.988 t-0.042 t^{2} \\
& F(P D)_{l}=-0.121+0.408 t \\
& F(P D)_{q}=-0.553+0.624 t-0.022 t^{2}
\end{aligned}
$$

where $F(B), F(S), F(L E)$ and $F(P D)$ indicate the fatigue based on Borg's CR-10 scale, SPFS SOFI (LE), and SOFI (PD) respectively. The suffixes I and q represent linear and quadratic variants, while $t$ is the duration of work in hours. The SE and $R^{2}$ values of these models are shown in Table 5.

Table 5: Reliability of models for predicting fatigue

\begin{tabular}{|lllllllll|}
\hline \multirow{2}{*}{ Criteria } & \multicolumn{2}{c}{$\begin{array}{c}\text { Borg's CR-10 } \\
\text { Scale }\end{array}$} & \multicolumn{2}{c|}{ SPFS } & \multicolumn{2}{c|}{ SOFI (LE) } & \multicolumn{2}{c|}{ SOFI (PD) } \\
\cline { 2 - 9 } & Linear & Quadratic Linear Quadratic & Linear & Quadratic Linear & Quadratic \\
\hline Standard error $(S E)$ & 0.118 & 0.075 & 0.193 & 0.239 & 0.257 & 0.136 & 0.125 & 0.040 \\
\hline Coefficient of determination $\left(R^{2}\right)$ & 0.998 & 1.000 & 0.983 & 0.987 & 0.980 & 0.997 & 0.991 & 1.000 \\
\hline
\end{tabular}

As shown, the SE of the mean values obtained by using Borg's CR-10 scale in the quadratic regression model is found to be less than for its linear model and for that obtained by using SPFS. Moreover, the coefficient of determination obtained in the quadratic model was the maximum, with a value of ' 1 ' in the case of Borg's CR-10 scale. Hence Borg's CR-10 scale with the quadratic model was used for predicting fatigue. Also, the normal probability plots of residuals in the quadratic models (Figure 3 ) indicate a smaller departure from a straight line in the case of Borg's CR-10 scale than that of SPFS.

Also as shown in Table 5, the SE of the mean values obtained by using SOFI (PD) in the quadratic regression model is found to be less than that in its linear model and than that obtained by using SOFI (LE). Moreover, $R^{2}$ in the quadratic model obtained against the mean values for SOFI (PD) was the maximum, with a value of 1 . Thus the SOFI (PD) dimension of fatigue could be predicted with more reliability than by the SOFI (LE) dimension by using the quadratic regression model. As shown in Figure 3, the residuals of the individual values of fatigue indicate a smaller departure from a straight line in the case of SOFI (PD) than for that of SOFI (LE). 
The prediction of fatigue based on Borg's CR-10 scale is shown graphically in Figure 4. The predicted values of fatigue for an extended working day of $9,10,11$, and 12 hours of work are 7.06, 7.77, 8.44 , and 9.07 respectively. The maximum exertion value of 10 in Borg's CR-10 scale is reached at 13.58 hours. The model also indicates that fatigue starts only after 0.94 hours of work.

The predictions of the PD dimension and the LE dimension of fatigue are shown graphically in Figure 5. In an extended working day of 12 hours, the fatigue would be 3.83 for the PD dimension and 5.30 for the LE dimension, according to SOFI. The models also indicate that the PD dimension of fatigue starts at 0.92 hours, while the LE dimension of fatigue starts only at 0.50 hours.
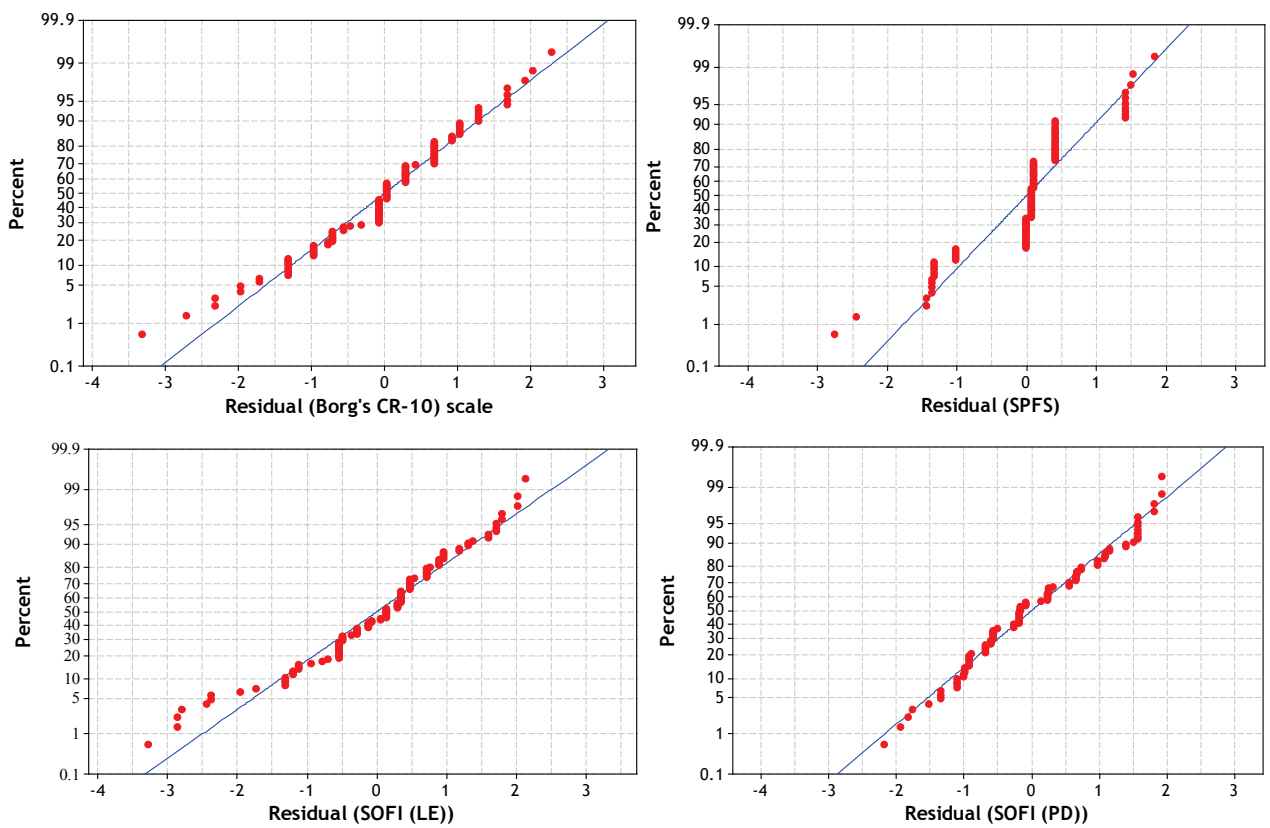

Figure 3: Normal probability plots of residuals (quadratic model) in fatigue measures (see online version for colour image)

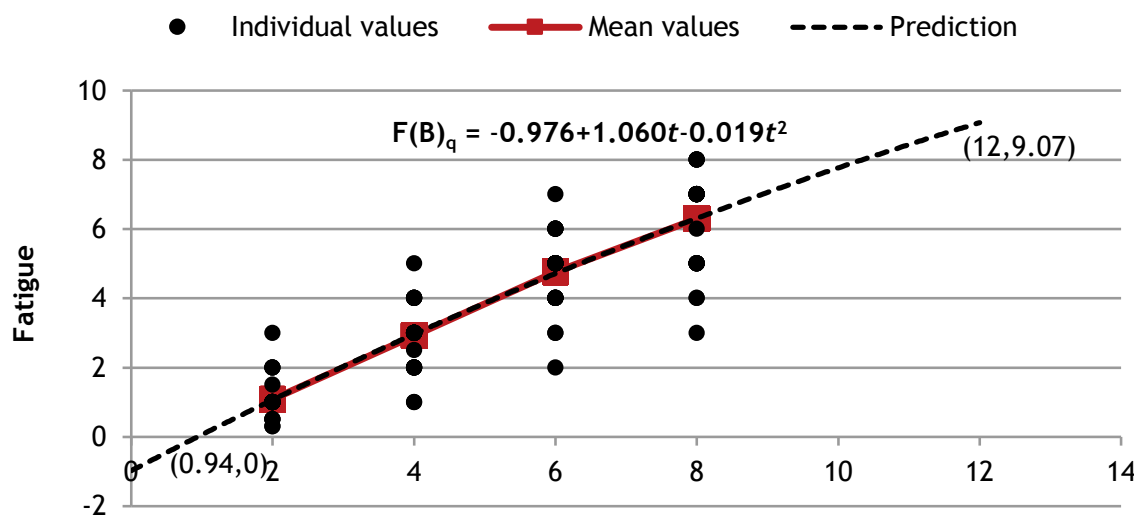

Time in hours $(t)$

Figure 4: Prediction of fatigue using Borg's CR-10 scale 


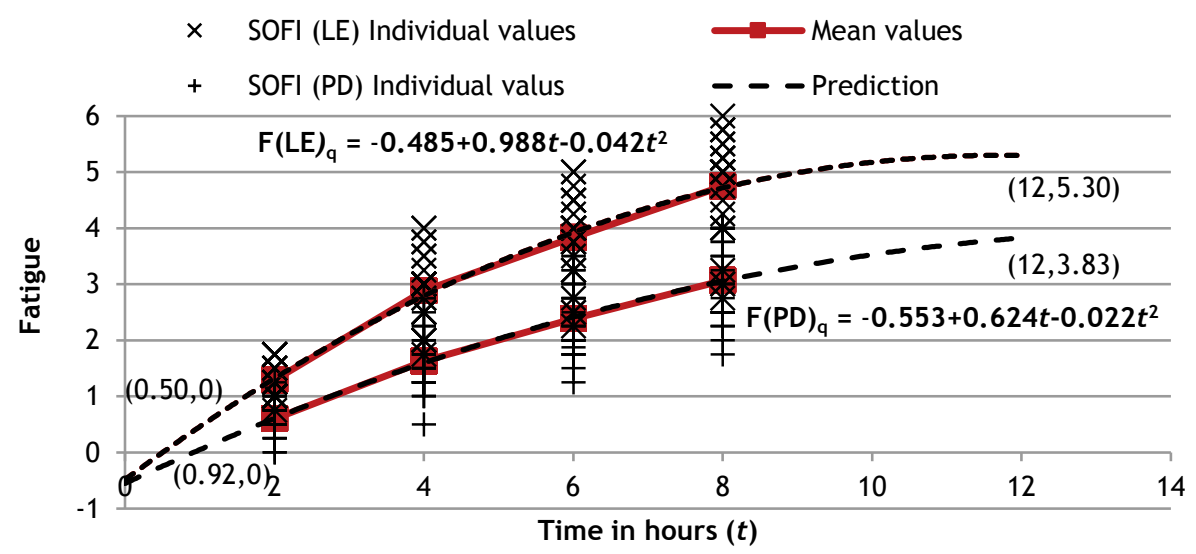

Figure 5: Prediction of SOFI dimensions (see online version for colour image)

\subsection{Prediction of fatigue and demographic characteristics}

The subjects are classified using demographic characteristics such as age, experience, and BMI. Spearman's rank correlation coefficient was used to determine the degree of the association of these variables. 'Experience' and 'BMl' indicated a significant $(p<0.05)$ correlation of 0.733 and 0.392 respectively with the age of the studied subjects. The correlation of 'experience' with 'BMl' was insignificant $(p>0.05)$ with a value of 0.138 .

Based on the age of the subjects, they were classified into two age groups: a younger group (subjects younger than 40 years) and an older group (subjects aged 40 years and over). There were 17 subjects in the younger group, and 13 in the older group. The Mann-Whitney test was used to compare the significance of difference in time-related fatigue in these groups. The results are shown in Table 6.

Table 6: Comparison of fatigue in the age, experience, and BMI groups

\begin{tabular}{|c|c|c|c|c|c|c|}
\hline \multirow{2}{*}{$\begin{array}{l}\text { Demographic } \\
\text { groups }\end{array}$} & \multirow{2}{*}{ Tests } & \multirow{2}{*}{ Results } & \multicolumn{3}{|c|}{ Time spent at work (hours) } & \multirow[b]{2}{*}{8} \\
\hline & & & 2 & 4 & 6 & \\
\hline \multirow{2}{*}{ Age groups } & \multirow{4}{*}{$\begin{array}{l}\text { Mann- } \\
\text { Whitney test }\end{array}$} & W-values & 254.0 & 229.0 & 217.5 & 213.5 \\
\hline & & p-values & 0.653 & 0.130 & $0.043^{*}$ & $0.026^{*}$ \\
\hline \multirow{2}{*}{$\begin{array}{l}\text { Experience } \\
\text { groups }\end{array}$} & & W-values & 268.0 & 234.5 & 234.0 & 238.0 \\
\hline & & p-values & 0.596 & $0.048^{*}$ & $0.045^{*}$ & 0.065 \\
\hline \multirow{2}{*}{ BMI groups } & \multirow{2}{*}{$\begin{array}{l}\text { Kruskal- } \\
\text { Wallis test }\end{array}$} & $\mathrm{H}$-values & 5.260 & 0.390 & 0.240 & 0.510 \\
\hline & & $\mathrm{p}$-values & 0.072 & 0.822 & 0.889 & 0.774 \\
\hline
\end{tabular}

These results indicate that no significant change of fatigue occurred in either the younger or the older group after two hours, not after four hours of work. However, there is significant $(p<0.05)$ change of fatigue after six and eight hours of work. The data was fitted with the quadratic regression models in the age groups in order to predict time-related fatigue. The equations thus obtained are presented below as Equation (9) and Equation (10) for the younger and older groups respectively.

$$
\begin{aligned}
& F(Y)=-0.838+0.953 t-0.015 t^{2} \\
& F(O)=-1.156+1.200 t-0.024 t^{2}
\end{aligned}
$$

where $F(Y)$ indicates the fatigue of the younger group, $F(0)$ indicates the fatigue of the older group, and $t$ is the duration of work in hours. The mean values of fatigue and its predicted curves are shown in Figure 6. As shown, fatigue in the younger group indicates a lower rate, whereas in the case of the older group a higher rate of fatigue is indicated. The older group reaches a value close to the maximum exertion of 10 after 12 hours of work, while the younger group only exceeds 8 in Borg's CR-10 scale. The initial values of the two groups intersect at 1.35 hours, with a minimum fatigue level value of 0.42 . The models provide a reliability with $R^{2}$ value of $0.999(\mathrm{SE}=0.092)$ and 1 (SE = 0.533 ) in the younger and older groups respectively. 


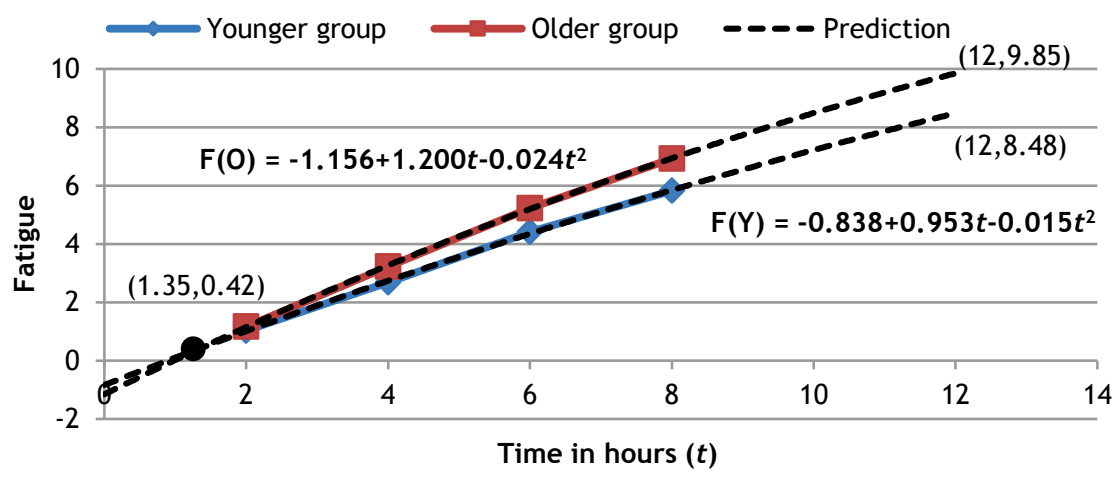

Figure 6: Prediction of fatigue with respect to age groups (see online version for colour image)

The subjects were also classified into two groups based on experience: a less-experienced group (subjects with less than 10 years of experience) and a more-experienced group (subjects with 10 years and more). There were 18 subjects in the less-experienced group and 12 subjects in the moreexperienced group. The Mann-Whitney test was used to compare the significance of the difference in fatigue in these groups. The results are shown in Table 6 . These results indicate no significant difference of fatigue in these groups after two hours of work. However, the difference in fatigue is significant after four and six hours of work. The data was fitted with the quadratic regression models in these groups in order to predict fatigue based on the time taken to execute the task. The regression equations are presented as Equation (11) and Equation (12) for the less-experienced group and the more-experienced group respectively.

$$
\begin{aligned}
& F(L)=-0.768+0.911 t-0.009 t^{2} \\
& F(M)=-1.287+1.284 t-0.032 t^{2}
\end{aligned}
$$

where $F(L)$ indicates the fatigue of the less-experienced group, $F(M)$ indicates the fatigue of the more-experienced group, and $t$ is the duration of work in hours. The less-experienced group and the more-experienced group exceed the value of 9 , with a value of 9.47 after 12 hours, while the lessexperienced group only exceeds the value of 8, with a value of 8.11 in Borg's CR-10 scale. The initial values of the two groups intersect at 1.53 hours, with an extremely weak fatigue level with a value of 0.6. These models provide reliability, with an $R^{2}$ value of $0.999(\mathrm{SE}=0.128)$ and $1(\mathrm{SE}=0.004)$ in the less-experienced and the more-experienced groups respectively. The mean values of fatigue and its predicted curves are shown in Figure 7. Fatigue in the less-experienced group indicates a lower rate, whereas in the case of the more-experienced group a higher rate of fatigue is indicated.

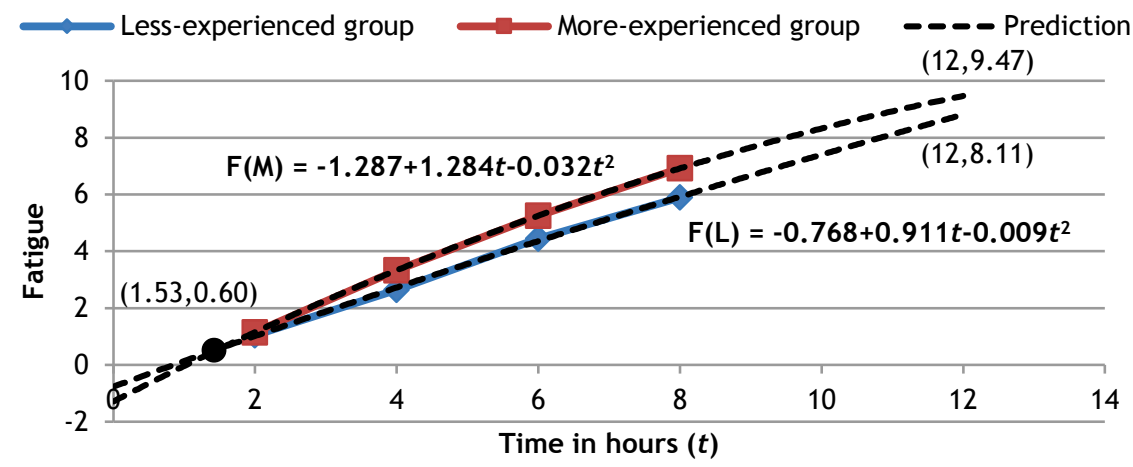

Figure 7: Prediction of fatigue in groups by experience (see online version for colour image)

The subjects were also classified into three groups based on their BMI: an underweight group (with a value below $18.5 \mathrm{~kg} / \mathrm{m}^{2}$ ), a normal weight group (with a value of $18.5 \mathrm{~kg} / \mathrm{m}^{2}$ and above, but below $23 \mathrm{~kg} / \mathrm{m}^{2}$ ), and an overweight and obese group (with a value of $23 \mathrm{~kg} / \mathrm{m}^{2}$ and above) [30]. There were five subjects in the underweight group, sixteen in the normal weight group, and nine in the overweight group. The Kruskal-Wallis test was conducted to determine the significance of the 
difference in fatigue in these groups. The results of this test are shown in Table 6, but indicate no significant difference of fatigue in these groups throughout the working day. The category-based fatigue prediction was not conducted for the BMI-based group, since it was found to be irrelevant for this group of subjects.

\section{DISCUSSION}

This study was conducted to assess the fatigue experienced by individual workers who are engaged in the assembly of submersible pumps while maintaining a stationary posture. Relevant data were collected at four times from the start of the working day, using Borg's CR-10, SPFS, and the taskrelevant dimensions of SOFI. All fatigue measures showed a significant $(p=0)$ increase in fatigue at every temporal point in the working day. It is also evident from Table 4 and Figure 2 that the rate of increase of fatigue decreases towards the end of the working hours in Borg's CR-10 scale and in the LE and PD dimensions of SOFI. Sato and Coury [31] reported that, in tasks with work variation, Borg's ratings of perceived exertion showed a non-linear behaviour of fatigue. Such behaviour can be expected in performing variable tasks, due to the changes in the work load. However, in this study, while performing the same task, a non-linear behaviour of fatigue was identified. This could be due to the effect of fatigue saturation in workers, or the effect of rest pauses. This observation is in tune with the work of Bosch, Mathiassen, Hallman, de Looze, Lyskov, Visser, and van Dieën [32], which supports the effect of rest pauses in restraining fatigue in industrial assembly tasks. A comparatively higher rate of fatigue in the first few hours of work may be due to the fact that the workers start work in the morning feeling fresh.

While using SPFS, the diminishing rate of time-related fatigue was not so evident. The level of fatigue perceived by the workers indicated a higher initial value in the early stages of the working day, and further increases to a higher value of ' 6 ' in a zigzag manner. Baulk, Fletcher, Kandelaars, Dawson, and Roach [19] report a similar variation in the fatigue measure in less labour-intensive tasks with extended hours of work, recording a maximum measure of fatigue that was lower than that reported here. The high value of SPFS at the end of the shift is probably due to the labourintensive nature of the task studied in this paper.

Borg's CR-10 scale indicated a significant $(p<0.05)$ correlation between all temporal values of fatigue, while it was not significant for all cases in SPFS (as reported in Table 3). The degree of the association of fatigue at temporal points of Borg's CR-10 scale is reflected in providing the maximum value of $R^{2}$ in the quadratic regression model. Also, the quadratic model of Borg's CR-10 scale provided a lower SE than its linear model. Thus the quadratic model of Borg's CR-10 scale was selected for this study to predict fatigue. For an extended working day of 12 hours, Borg's CR-10 scale indicates a value nearer to ' 9 ', which is lower than the maximum exertion. It indicates that the worker can continue his work in an extended working day without becoming fully exhausted. The SOFI dimensions PD and LE also indicate a maximum value of fatigue measure that is lower than the maximum scale value of ' 6 ' (Figure 5) in an extended working day of 12 hours. It is apparent from the prediction models of fatigue measures that the workers are free from fatigue at the start of work. This also supports the initial assumption made in the study. Small- and medium-scale pump manufacturing companies can attain the condition of starting the shift in a fresh condition because the workers are not working or forced to work in rotation shifts. This eliminates the inclusion of saturation and circadian effects in fatigue models, which complicate the issue [33].

The significant positive correlation between the ages of the subjects and their experience reveals that the older subjects have been engaged in this type of work for many years. However, the correlation between the age of the subjects and their BMI was found to be significant with a small value of correlation. This study reveals that the fatigue level of the older group of subjects is significantly higher than that for the younger group. It means that, even though the experienced workers have higher skills levels and higher levels of performance, they will become fatigued earlier than younger workers. However, the performance of the older workers will not be affected by fatigue as much as that of their younger counterparts [34]. Among the BMI-based groups, this study has found that there was no significant variation of fatigue throughout the working day. This indicates that $\mathrm{BMI}$ is not a significant determinant of fatigue. A similar result was reported by Zhang, $\mathrm{Li}$, Zhang, Ma, and Chen [35] in a study of muscle fatigue among industrial workers.

Only task-specific dimensions of SOFI such as LE and PD were considered for the measurement of fatigue in this study, even though the literature reports the use of all the SOFI dimensions in assessing 
fatigue [17, 22-23]. The other dimensions of SOFI - physical exertion, lack of motivation, and sleepiness - can also be included in studies to assess fatigue in similar industrial tasks. The extended working day of 12 hours is fixed for prediction purposes, based on the maximum allowable working hours, including rest periods, as stipulated in India's labour laws [36]. The studied industries work only in general shifts of eight hours, and extend them to meet the demands of production. Therefore, the prediction of fatigue up to a maximum of 12 hours a day is relevant in this study.

\section{CONCLUSION}

This study has revealed a diminishing rate of increase in time-related fatigue among workers doing overhead assembly. Borg's CR-10 scale has been found to be more reliable in predicting fatigue than SPFS. The PD dimension of SOFI is found to be a more dependable indicator of fatigue than the LE dimension in stationary assembly jobs involving overhead work. The earlier development of fatigue among older workers appears not to affect their performance more than that of younger workers. The work design of the selected job seems to be effective in limiting fatigue during working hours.

This study could be extended to include similar overhead tasks in order to determine the consistency of its results. The prediction models presented in this paper will help companies to set benchmarks for time-based strategies to limit fatigue. They will also help to reduce the prevalence of MSDs among industrial workers, even when working for extended hours.

\section{ACKNOWLEDGEMENTS}

The authors acknowledge the management and workers of the submersible pump manufacturing companies involved in this study for their co-operation and support.

\section{REFERENCES}

[1] Mossa, G., Boenzi, F., Digiesi, S., Mummolo, G. \& Romano, V.A. 2016. Productivity and ergonomic risk in human based production systems: A job-rotation scheduling model, International Journal of Production Economics, 171(4), pp. 471-477.

[2] Lekurwale, R.R., Akarte, M.M. \& Raut, D.N. 2014. Framework to evaluate manufacturing capability using analytical hierarchy process, The International Journal of Advanced Manufacturing Technology, 76, pp. 112.

[3] Greubel, J. \& Nachreiner, F. 2013. The validity of the risk index for comparing the accident risk associated with different work schedules, Accident Analysis and Prevention, 50, pp.1090-1095.

[4] Westgaard, R.H. \& Winkel, J. 1996. Guidelines for occupational musculoskeletal load as a basis for intervention: a critical review, Applied Ergonomics, 27, pp. 79-88.

[5] Hanklang, S., Kaewboonchoo, O., Silpasuwan, P. \& Mungarndee, S.S. 2012. Musculoskeletal disorders among Thai women in construction-related work, Asia-Pacific Journal of Public Health, 20, pp. 1-7.

[6] Meksawi, S., Tangtrakulwanich, B. \& Chongsuvivatwong, V. 2012. Musculoskeletal problems and ergonomic risk assessment in rubber tappers: A community-based study in southern Thailand, International Journal of Industrial Ergonomics, 42, pp. 129-135.

[7] Falck, A.-C., Örtengren, R. \& Rosenqvist, M. 2014. Assembly failures and action cost in relation to complexity level and assembly ergonomics in manual assembly (part 2), 44, pp. 455-459.

[8] Kamalinia, M., Saraji, G.N., Kee, D., Hosseini, M. \& Choobineh, A. 2013. Postural loading assessment in assembly workers of an Iranian telecommunication manufacturing company, International Journal of Occupational Safety and Ergonomics, 19, pp. 311-319.

[9] Grieve, J.R. \& Dickerson, C.R. 2008. Overhead work: Identification of evidence-based exposure guidelines, Occupational Ergonomics, 8, pp. 53-66.

[10] Bernard, B.P. (ed.). 1997. Musculoskeletal disorders and workplace factors: A critical review of epidemiologic evidence for work-related musculoskeletal disorders of the neck, upper extremity and low back, Cincinnati, USA: National Institute for Occupational Safety and Health.

[11] Bosch, T., Looze, M.P.D. \& Dieën, J.H.V. 2007. Development of fatigue and discomfort in the upper trapezius muscle during light manual work, Ergonomics, 50, pp. 161-177.

[12] Sood, D., Nussbam, M.A. \& Hager, K. 2007. Fatigue during prolonged intermittent overhead work: Reliability of measures and effects of working height, Ergonomics, 50, pp. 497-513.

[13] Kee, D. \& Lee, I. 2012. Relationships between subjective and objective measures in assessing postural stresses, Applied Ergonomics, 43, pp. 277-282.

[14] Ream, E. \& Richardson, A. 1996. Fatigue: A concept analysis, International Journal of Nursing Studies, 33, pp. 519-529.

[15] Åhsberg, E., Gamberale, F. \& Kjellberg, A. 1997. Perceived quality of fatigue during different occupational tasks: Development of a questionnaire, International Journal of Industrial Ergonomics vol. 20, pp. 121-135. 
[16] Borg, G. 1990. Psychophysical scaling with applications in physical work and the perception of exertion, Scand J Work Environ Health, 16, pp. 55-58.

[17] Ahmed, S., Babski-Reeves, K., DuBien, J., Webb, H. \& Strawderman, L. 2016. Fatigue differences between Asian and Western populations in prolonged mentally demanding work-tasks, International Journal of Industrial Ergonomics,54, pp. 103-112.

[18] Samn, S.W. \& Perelli, L.P. 1982 Estimating aircrew fatigue: A technique with application to airlift operations, Texas, USA: USAF School of Aerospace Medicine. SAM-TR-82-21.

[19] Baulk, S.D., Fletcher, A., Kandelaars, K.J., Dawson, D. \& Roach, G.D. 2009. A field study of sleep and fatigue in a regular rotating 12-h shift system, Applied Ergonomics, 40, pp. 694-698.

[20] Dorrian, J., Baulk, S.D. \& Dawson, D. 2011. Work hours, workload, sleep and fatigue in Australian rail industry employees, Applied Ergonomics, 42, pp. 202-209.

[21] Åhsberg, E. \& Gamberale, F. 1998. Perceived fatigue during physical work: An experimental evaluation of a fatigue inventory, International Journal of Industrial Ergonomics, 21, pp. 117-131.

[22] Gutiérez, J.L.G., Jiménez, B.M., Hernández, E.G. \& López, A.L. 2005. Spanish version of the Swedish Occupational Fatigue Inventory (SOFI): Factorial replication, reliability and validity, International Journal of Industrial Ergonomics, 35, pp. 737-746.

[23] Gershon, P., Shinar, D. \& Ronen, A. 2009. Evaluation of experience-based fatigue countermeasures, Accident Analysis \& Prevention, vol. 41, pp. 969-975.

[24] Dembe, A.E., Erickson, B., Delbos, R.G. \& Banks, S.M. 2005. The impact of overtime and long work hours on occupational injuries and illnesses: New evidence from the United States, Occup Environ Med, 62, pp. 588-597.

[25] Caruso, C.C. 2006. Possible broad impacts of long work hours, Industrial Health, 44, pp. 531-36.

[26] Sato, Y., Miyake, H. \& Thériault, G. 2009. Overtime work and stress response in a group of Japanese workers, Occupational Medicine, 59, pp. 14-19.

[27] Virtanen, M., Ferrie, J.E., Singh-Manoux, A., Shipley, M.J., Vahtera, J., Marmot, M.G. \& Kivimäki, M. 2010. Overtime work and incident coronary heart disease: TheWhitehall II prospective cohort study, European Heart Journal, 31, pp. 1737-1744.

[28] Parkes, K.R. 2012. Shift schedules on North Sea oil/gas installations: A systematic review of their impact on performance, safety and health, Safety Science, 50, pp. 1636-1651.

[29] Borg, G. 1998. Borg's perceived exertion and pain scales. Champaign, IL: Human Kinetics.

[30] Annurad, E. \& Shivakku, K. 2003. New BMl criteria for Asians by regional office of WHO,Journal of Ocuupational Health, 45, pp. 335-343.

[31] Sato, T.d'O. \& Coury, H.J.C.G. 2009. Evaluation of musculoskeletal health outcomes in the context of job rotation and multifunctional jobs, Applied Ergonomics, 40, pp. 707-712.

[32] Bosch, T., Mathiassen, S.E., Hallman, D., de Looze, M.P., Lyskov, E., Visser, B. \& van Dieën, J.H. 2012. Temporal strategy and performance during a fatiguing short-cycle repetitive task, Ergonomics, 55, pp. 863873.

[33] Dawson, D. \& Fletcher, A. 2001. A quantitative model of work-related fatigue: Background and definition, Ergonomics, 44, pp. 144-163.

[34] Mehta, R.K. \& Agnew, M.J. 2010. Analysis of individual and occupational risk factors on task performance and biomechanical demands for a simulated drilling task, International Journal of Industrial Ergonomics, 40, pp. 584-591.

[35] Zhang, Z., Li, K.W., Zhang, W., Ma, L. \& Chen, Z. 2014. Muscular fatigue and maximum endurance time assessment for male and female industrial workers, International Journal of Industrial Ergonomics, 44, pp. 292-297.

[36] ILO. 1987. NATLEX Database: India - The Factories Act, 1948 (Act No. 63 of 1948), as amended by the Factories (Amendment) Act, 1987 (Act 20 of 1987), Section 56, Available: http://www.ilo.org/dyn/natlex/docs/WEBTEXT/32063/64873/E87IND01.htm. (Accessed 19 February 2014) 